\title{
The plasma bioavailability of nitrate and betanin from Beta vulgaris rubra in humans
}

\author{
Tom Clifford ${ }^{1} \cdot$ Costas M. Constantinou $^{1} \cdot$ Karen M. Keane $^{1} \cdot$ Daniel J. West $^{2}$. \\ Glyn Howatson $^{1,3} \cdot$ Emma J. Stevenson ${ }^{2}$
}

Received: 22 October 2015 / Accepted: 2 February 2016 / Published online: 12 February 2016

(C) The Author(s) 2016. This article is published with open access at Springerlink.com

\begin{abstract}
Purpose To evaluate the plasma bioavailability of betanin and nitric oxide (NOx) after consuming beetroot juice (BTJ) and whole beetroot (BF). BTJ and BF were also analysed for antioxidant capacity, polyphenol content (TPC) and betalain content.

Methods Ten healthy males consumed either $250 \mathrm{ml}$ of BTJ, $300 \mathrm{~g}$ of BF or a placebo drink, in a randomised, crossover design. Venous plasma samples were collected pre (baseline), 1, 2, 3, 5 and $8 \mathrm{~h}$ post-ingestion. Betanin content in BTJ, BF and plasma was analysed with reverse-phase high-performance liquid chromatography (HPLC) and mass spectrometry detection (LCMS). Antioxidant capacity was estimated using the Trolox equivalent antioxidant capacity (TEAC) and polyphenol content using Folin-Ciocalteu colorimetric methods [gallic acid equivalents (GAE)] and betalain content spectrophotometrically.

Results TEAC was $11.4 \pm 0.2 \mathrm{mmol} / \mathrm{L}$ for $\mathrm{BTJ}$ and $3.4 \pm 0.4 \mu \mathrm{mol} / \mathrm{g}$ for BF. Both BTJ and BF contained a number of polyphenols $(1606.9 \pm 151 \mathrm{mg} / \mathrm{GAE} / \mathrm{L}$ and $1.67 \pm 0.1 \mathrm{mg} / \mathrm{GAE} / \mathrm{g}$, respectively), betacyanins $(68.2 \pm 0.4 \mathrm{mg} /$ betanin equivalents $/ \mathrm{L}$ and $19.6 \pm 0.6 \mathrm{mg} /$ betanin equivalents/100 g, respectively) and betaxanthins
\end{abstract}

Tom Clifford

tom.clifford@northumbria.ac.uk

1 Department of Sport, Exercise and Rehabilitation, Faculty of Health and Life Sciences, Northumbria University, Newcastle-upon-Tyne NE1 8ST, UK

2 Institute of Cellular Medicine, Newcastle University, Newcastle-upon-Tyne, UK

3 Water Research Group, School of Environmental Sciences and Development, Northwest University, Potchefstroom, South Africa
$(41.7 \quad \pm \quad 0.7 \quad \mathrm{mg} /$ indicaxanthin equivalents/L and $7.5 \pm 0.2 \mathrm{mg} /$ indicaxanthin equivalents $/ 100 \mathrm{~g}$, respectively). Despite high betanin contents in both BTJ $(\sim 194 \mathrm{mg})$ and BF ( $\sim 66 \mathrm{mg})$, betanin could not be detected in the plasma at any time point post-ingestion. Plasma NOx was elevated above baseline for $8 \mathrm{~h}$ after consuming BTJ and $5 \mathrm{~h}$ after $\mathrm{BF}(P<0.05)$.

Conclusions These data reveal that BTJ and BF are rich in phytonutrients and may provide a useful means of increasing plasma NOx bioavailability. However, betanin, the major betalain in beetroot, showed poor bioavailability in plasma.

Keywords Beetroot $\cdot$ Betalains $\cdot$ Nitric oxide . Antioxidant $\cdot$ Bioavailability

\section{Introduction}

The root vegetable, red beetroot (Beta vulgaris rubra), is a functional food that has attracted much attention over the last decade, with particular focus on its potential health benefits (for review, see [1, 2]). The interest in beetroot has been largely driven by its nitrate content, which is proposed to be $\sim 1459 \mathrm{mg} \mathrm{kg}^{-1}$ DW [3]. Dietary nitrate may confer beneficial health effects via its sequential reduction to nitrite and nitric oxide (NOx), a pleiotropic molecule that plays a key role in the regulation of vascular homoeostasis, immune function and metabolism [4, 5]. There are now several reports that acute consumption of beetroot can stimulate endogenous NOx production and evoke positive changes in endothelial function and blood pressure [6-8]. Consequently, beetroot is currently purported as a health promoting food that might be useful for reducing the risk of developing cardiovascular diseases (i.e. hypertension 


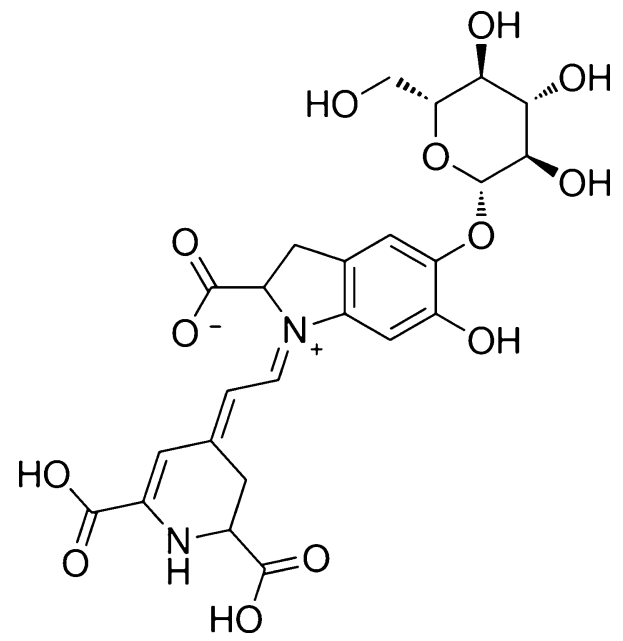

Fig. 1 Chemical structure of betanin (betanidin 5-O-b-glucoside)

and stroke) and immune disorders (i.e. inflammatory bowel disease) $[2,3,9]$.

Nitrate is not the only constituent of beetroot that may have beneficial effects for health. As well as being a good source of polyphenols, beetroot contains a group of betalamic acid derivatives known as betalains [10]. The betalains derive from the plant order Caryophyllales and are categorised as either betacyanins, which are responsible for the red/violet colour of red beetroot or betaxanthins, which are yellow in colour $[1,11]$. Betalains are water-soluble phytochemicals that have been shown to possess antiinflammatory, antioxidant and chemo-preventive activities in vitro $[1,10,12,13]$. In recent years, there has been a particular interest in the biochemical activity of betanin (betanidin 5-O-b-glucoside; chemical structure depicted by Fig. 1), which is the most abundant betacyanin in beetroot (300-600 mg/kg uncooked), and the main constituent of the food colourant E162 [10, 14-16]. As a cationised compound, betanin is a highly effective scavenger of reactive oxygen species (ROS) $[14,17]$. Betanin also possesses antiinflammatory properties; betanin and its aglycone betanidin were shown to modulate lipoxygenase and cyclooxygenase activity in vitro, indicating that betanin might downregulate pro-inflammatory signalling [13]. These findings have led to interest in the role of beetroot in the protection against the potentially damaging effects of ROS and aberrant immune function $[18,19]$.

An increased awareness of beetroot's potential health benefits, together with an increased demand for convenient health foods, has led to the development of a number of beetroot-based functional food products. Throughout the world, beetroot can now be purchased as a concentrated juice drink or as a ready to consume precooked snack, bypassing the need for prior cooking. Given the wide array of bioactive compounds present in beetroot, it is possible that regular consumption of these products could have favourable effects for health and well-being. Furthermore, these products might have applications as dietary supplements in the management of a host of chronic and degenerative disorders, including hypertension, osteoarthritis and numerous cancers $[1,9,20]$. However, in order to evaluate the potential usefulness of these products in the promotion of general health or as therapeutic agents, information on their in vivo bioavailability and phytochemical content in humans is required.

Dietary nitrate is believed to be highly bioavailable [21], and increases in the plasma have been observed following ingestion of beetroot juice [8, 22]. Betalains, in contrast, are thought to have much lower bioavailability [23]; however, no published studies have characterised the bioavailability of betalains in plasma from consuming commercially available beetroot products. Collectively, these data would provide novel and readily accessible information to both consumers and practitioners (i.e. nutritionists, dieticians, physiologists and other health professionals) who may be interested in the potential health benefits of commercially available functional foods, like beetroot.

Consequently, the main objective of this study was to determine the acute plasma bioavailability of betanin, the major betalain in beetroot, and nitrate, a precursor for NOx activity, in human plasma after consuming both beetroot juice (BTJ) and beetroot whole food (BF). A secondary aim was to characterise the antioxidant capacity, polyphenol and betalain content of BTJ and BF.

\section{Methods}

\section{Participants}

Ten healthy, non-smoking males (age $23 \pm 3$ years; height $1.82 \pm 0.60 \mathrm{~m}$; mass $78.8 \pm 6.7 \mathrm{~kg}$ ) were recruited to participate in this study. Participants were excluded from the study if they had any known food allergies, were taking medication (including dietary supplements), or were suffering from or have previous history of renal, gastrointestinal or cardiovascular complications or any other contraindication to the study procedures. All participants were made aware that their participation was voluntary and that they were free to withdraw at any time. The study protocol received institutional ethical approval. Each participant provided written informed consent prior to study entry.

\section{Experimental design}

Subjects were required to attend the laboratory on 3 occasions, separated by 7 days. In the $48 \mathrm{~h}$ prior to each visit, subjects followed a low phenolic and betalanic diet. This 
included avoiding all vegetables, cured meats, fruits and their juices, chocolate, wholegrain breads and grains, caffeinated beverages including all varieties of tea, coffee and alcohol. To ensure compliance, subjects were given a written list of foods to avoid and diaries to record their intake $48 \mathrm{~h}$ prior to the first trial. They were instructed to replicate this diet as closely as possible in the $48 \mathrm{~h}$ before the remaining two trials. For each trial, subjects attended the laboratory between the hours of 07:00-09:00 following a 12-h overnight fast and had a cannula inserted into a vein at the antecubital fossa. After a baseline blood sample, subjects were given 1 of 3 treatments; beetroot juice $(250 \mathrm{ml})$, an isocaloric placebo $(250 \mathrm{ml})$ or cooked beetroot $(300 \mathrm{~g})$ in a randomised, crossover fashion (see Table 1). Further blood samples were drawn at 1, 2, 3, 5 and $8 \mathrm{~h}$ after ingesting the treatments (see Fig. 2 for schematic) to ascertain the pharmacokinetics of the compounds of interest. Subjects were not allowed to consume any food until testing was complete but were allowed water ad libitum; the amount of water consumed on the first trial was recorded and replicated in the subsequent trials.

\section{Blood sampling procedures}

At each time point, $10 \mathrm{ml}$ of venous blood was collected into EDTA treated tubes (Vacutainer, Bendict Dickinson) and immediately centrifuged at $3000 \mathrm{~g}\left(4^{\circ}\right)$ for 10 min to separate plasma. Samples were aspirated into a series of aliquots and stored immediately at $-80{ }^{\circ} \mathrm{C}$ until analysis.

Table 1 Nutrient composition of treatment beverages

\begin{tabular}{llll}
\hline Treatment & BTJ & BF & PLA \\
\hline Energy (Kcals) & 81 & 126 & 76.8 \\
Volume & $250 \mathrm{ml}$ & $300 \mathrm{~g}$ & $250 \mathrm{ml}$ \\
Carbohydrate $(\mathrm{g})$ & 16.4 & 23.1 & 16.4 \\
Protein $(\mathrm{g})$ & 2.8 & 3.6 & 2.8 \\
Fat $(\mathrm{g})$ & 0.4 & 0.6 & Trace \\
Nitrate $(\mathrm{mg})$ & $\sim 250.6 \mathrm{mg}$ & N/A & Trace \\
\hline
\end{tabular}

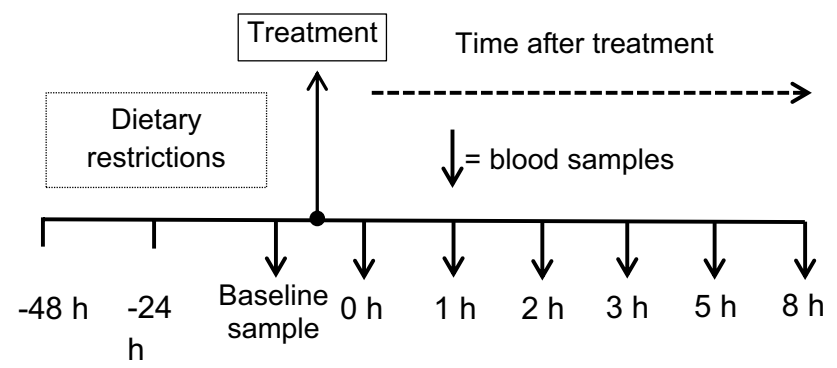

Fig. 2 Schematic outline of bioavailability study procedures

\section{Supplementation}

Nutritional composition of the 3 treatments is provided in Table 1. The beetroot juice (Love Beets Super Tasty Beetroot Juice, Gs Fresh Ltd., Cambridgeshire, UK) and the whole beetroot food were freshly cooked and prepacked (Tesco PLC, Hertfordshire, UK). Both the beetroot juice and beetroot food originated from the same manufacturer (Gs Fresh Ltd., Cambridgeshire, UK). The placebo (PLA) beverage contained a commercially available fruit $<1 \%$ squash (Kia Ora, Coca Cola Enterprises, Uxbridge, UK) with negligible phytochemical and nitrate content and was fortified with maltodextrin (Myprotein, Manchester, UK) flavourless protein powder (Arla Foods, Amba, Denmark) and water, to match the BTJ for volume and macro-nutrient content. The quantification of nitrate in the BTJ was performed by Gs Fresh Ltd; however, data on the nitrate content of BF were not available.

\section{Antioxidant activity and phenolic content}

Extracts of the whole beetroot samples in 80:20 methanol:water, and mixtures of placebo and beetroot juice in the same solvent were used to determine their total phenolic content (TPC) and antioxidant activity (TEAC). For the beetroot food, samples (about $10 \mathrm{~g}$ of whole beetroot) were cryogenically milled in liquid nitrogen using an IKA A11 S2 analytical mill (IKA Works, Wilmington, USA). Accurate amounts of frozen powder (500-700 mg) were extracted five times with $1 \mathrm{~mL}$ 80:20 methanol:water, filtered and combined to a total volume of $5 \mathrm{~mL}$, whilst the liquid materials (juice and placebo) were diluted (1:10) in the extraction solvent.

A modified 2,2-diphenyl-1-picrylhydrazyl (DPPH) assay used for antioxidant activity measurements was adjusted for use in the present study [24]. The DPPH solution was prepared freshly before the analysis, by dissolving the DPPH reagent $(2.4 \mathrm{mg})$ in $80 \%$ methanol $(100 \mathrm{~mL})$. Samples were further diluted in deionised water (1:10 or 1:100) and $10 \mu \mathrm{L}$ of sample; $40 \mu \mathrm{L}$ of deionised water and $200 \mu \mathrm{L}$ of DPPH solution were added into each well of the CELLSTAR 96 well plate (Greiner Bio-One, Monroe, USA). Absorbance readings were taken at $515 \mathrm{~nm}$, at 3-min intervals over a 30 -min period at $37{ }^{\circ} \mathrm{C}$, using a BioTek Synergy HT Multi-Mode Microplate Reader (BioTek, Winooski, USA). A calibration curve using Trolox $(0-500 \mu \mathrm{M}$, $\left.R^{2}=0.99\right)$ was plotted. Final values are expressed as means of Trolox equivalents per milligram of sample \pm SD for 6 replicants.

Total phenolic content (TPC) was measured using a modified Folin-Ciocalteu colourimetric method [25, 26]. Samples were diluted in deionised water $(1: 10$ or 
1:100) and $50 \mu \mathrm{L}$ of the diluted extract; $50 \mu \mathrm{L}$ of FolinCiocalteu reagent diluted in water $(1: 25)$ and $100 \mu \mathrm{L}$ of $6 \%(\mathrm{w} / \mathrm{v})$ sodium carbonate were added into corresponding sample wells of a 96-well plate (Greiner BioOne, Monroe, USA). Absorbance readings were taken at $725 \mathrm{~nm}$, at 5-min intervals, over a 30 -min period at $25{ }^{\circ} \mathrm{C}$ using a BioTek Synergy HT Multi-Mode Microplate Reader (BioTek, Winooski, USA). A stock solution of gallic acid $(5.9 \mathrm{mM})$ was prepared in aqueous methanol $(80 \%(\mathrm{v} / \mathrm{v})$, and quantification was performed on the basis of a standard curve in the range $0-50 \mathrm{mg} /$ $\mathrm{mL}\left(R^{2}=0.99\right)$. The analysed samples were measured versus a blank sample. All values are expressed as means of gallic acid equivalents per gram of sample \pm SD for 6 replicants.

\section{Total betanin and betaxanthin content}

The content of betaxanthins and betacyanins in the buffered extract and 1:10 juice solutions in aqueous McIlvaine buffer (pH 6.5) was determined at $538 \mathrm{~nm}$ and $480 \mathrm{~nm}$ with a UV-Vis spectrometer (Ultrospec 2000 UV/Vis spectrophotometer, Pharmacia Biotech, Sweden), respectively, according to the methods of Cai and Corke [27] and Mossamer et al. [28]. Total betalains were quantified using the following equation: $\mathrm{BLC}[\mathrm{mg} / \mathrm{L}]=(A \times \mathrm{DF} \times \mathrm{MW} \times 1000) /$ $(\varepsilon \times 1)$, where $A$ is the absorption value at the absorption maximum, DF the dilution factor and 1 the path length $(1 \mathrm{~cm})$ of the cuvette. For quantification of betacyanins $(\mathrm{Bc})$ and betaxanthins $(\mathrm{Bx})$, the molecular weights $(\mathrm{MW})$ and molar extinction coefficients $(\varepsilon)$ of betanin (MW $=550 \mathrm{~g}$ / $\mathrm{mol} ; \varepsilon=60,000 \mathrm{~L} / \mathrm{mol} \mathrm{cm} ; \lambda=538 \mathrm{~nm}$ ) and indicaxanthin $(\mathrm{MW}=308 \mathrm{~g} / \mathrm{mol} ; \varepsilon=48,000 \mathrm{~L} / \mathrm{mol} \mathrm{cm} ; \lambda=480 \mathrm{~nm})$ were applied, respectively.

\section{Extraction of whole beetroot betalains}

A previously described method $[29,30]$ was used for betalain extraction of whole beetroots. Samples (about $10 \mathrm{~g}$ of whole beetroot) were cryogenically milled in liquid nitrogen using an IKA A11 S2 analytical mill (IKA Works, Wilmington, USA). Accurate amounts of frozen powder (500-600 mg) were transferred in a 15-mL Falcon tube and homogenised with $1 \mathrm{~mL}$ water for $5 \mathrm{~min}$ (Whirlimixer, FisherBrand, Fisher Scientific, UK). The homogenate was centrifuged for $15 \mathrm{~min}$ at $3000 \mathrm{rpm}$, and the supernatant was collected. The insoluble part was re-extracted with $1 \mathrm{~mL}$ of water for a total of five times. The extracts were combined, and the water was removed using a rotary evaporator, coupled to a heated water bath under vacuum (STUART, Bibby Scientific, Staffordshire, UK) and re-dissolved in McIlvaine buffer (pH 6.5, $10 \mathrm{~mL}$ ).

\section{Extraction of beetroot food for betanin determination}

Betanin standard was purchased from Adooq Bioscience (California, USA). Beetroot samples (about $20 \mathrm{~g}$ of whole beetroot) were cryogenically milled in liquid nitrogen using an IKA A11 S2 analytical mill (IKA Works, Wilmington, USA). Accurate amounts of frozen powder (200$300 \mathrm{mg}$ ) were transferred in a $15-\mathrm{mL}$ Falcon tube and homogenised with $1 \mathrm{~mL}$ water for $5 \mathrm{~min}$ (Whirlimixer, FisherBrand, Fisher Scientific, UK). The homogenate was centrifuged for $15 \mathrm{~min}$ at $3000 \mathrm{rpm}$, and the supernatant was collected. The insoluble part was re-extracted with $1 \mathrm{~mL}$ of water for a total of five times. The extracts were combined, and the water was removed using a rotary evaporator, coupled to a heated water bath under vacuum (STUART, Bibby Scientific, Staffordshire, UK). Finally, the extracts were re-dissolved in water $(10 \mathrm{~mL})$, filtered and diluted further prior to LC-MS analysis (1:100 in mobile phase A). All experiments were performed in sixplicate.

\section{LCMS for betanin determination}

Betanin determination of diluted beetroot juice samples $(2.5 \mathrm{mg} / \mathrm{mL}$ in $1: 10.1 \%$ formic acid in water: $2 \% \mathrm{HCl}$ in $\mathrm{MeOH}$ ) and beetroot food extracts was carried out on a Dionex UltiMate 3000 RSLC HPLC System (Dionex, Camberley, UK) equipped with an UltiMate 3000 RS pump, an UltiMate $3000 \mathrm{RS}$ autosampler and a QExactive Quadrupole-Orbitrap Mass Spectrometer (Thermo Fisher Scientific, Waltham, USA). Electrospray ionisation at negative ion mode was performed with a spray voltage of $2.00 \mathrm{kV}$ and capillary temperature of $280{ }^{\circ} \mathrm{C}$. The total ion current (TIC) with a range of $100-1000 \mathrm{~m} / \mathrm{z}$ and 70,000 resolution was measured. The ion $\mathrm{m} / \mathrm{z} 549$ was used for quantification of betanin. Sample aliquots $(3 \mu \mathrm{L})$ were injected on a Phenomenex Luna C18(2) $(250 \times 2.0 \mathrm{~mm}$, 5um particle size) reverse-phase column thermostatically regulated at $40{ }^{\circ} \mathrm{C}$. The mobile phase consisted of water with $1 \%$ acetic acid (solvent $\mathrm{A}$ ), and acetonitrile with $1 \%$ acetic acid (solvent B). After a 6-min equilibration with $20 \% \mathrm{~B}$, the elution programme was as follows: $0-30 \mathrm{~min}$, $10-100 \% \mathrm{~B},(0.2 \mathrm{~mL} / \mathrm{min})$ followed by a washing stage (100\% B, 30-36 min, $0.2 \mathrm{~mL} / \mathrm{min})$ and re-equilibration at the initial conditions for $3 \mathrm{~min}$. Betanin with a retention time of 2.56 min was quantified by external standard determination.

\section{Extraction of plasma for betanin determination}

Several attempts to extract betanin from plasma samples were performed: (a) $1 \mathrm{~mL}$ of plasma was mixed with $4 \mathrm{~mL}$ 
oxalic Acid (10 nM) and $0.1 \mathrm{~mL} \mathrm{HCl}(12.6 \mathrm{M})$ in $15-\mathrm{mL}$ Falcon tubes and centrifuged at $826 \mathrm{~g}$ for $5 \mathrm{~min}$. The supernatant was absorbed on to a primed solid-phase extraction cartridge (Waters Sep-Pak c17 plus short cartridge, $360 \mathrm{mg}$ sorbent per cartridge, 55-105 $\mu \mathrm{m}$ ), washed with methanol $+0.2 \%$ trifluoroacetic acid (TFA) followed by $2 \times 5 \mathrm{~mL}$ of water. The sample was eluted with $3 \mathrm{~mL}$ of $\mathrm{MeOH}+0.2 \%$ TFA, dried under N2 at $45{ }^{\circ} \mathrm{C}$. Samples were then reconstituted in $400 \mu \mathrm{l}$ of solvent F: $0.1 \%$ formic acid in water: $2 \% \mathrm{HCl}$ in methanol and filtered through a 0.2- $\mu \mathrm{m}$ polytetrafluoroethylene filter prior to HPLC and LC-MS analyses; (b) $1 \mathrm{~mL}$ of plasma was extracted with $4 \mathrm{~mL} \mathrm{1:1}$ acetonitrile:water for $10 \mathrm{~min}$ and centrifuged for $10 \mathrm{~min}$ at $3000 \mathrm{rpm}$. The supernatant was collected, evaporated to dryness, reconstituted in 1:1 acetonitrile: water and filtered in autosampler vials. Three types of plasma samples were analysed using the above two methods as well as with variations, samples obtained from test subjects after consumption of beetroot food, beetroot juice and placebo, at various time points, and analysed using HPLC/UV/Vis/ FLD and LCMS methodologies.

\section{Analysis of plasma $\mathrm{NO}_{\mathrm{x}}$}

Plasma NOx bioavailability was determined from plasma nitrate and nitrite concentrations using a standard assay kit (R\&D Systems, Minneapolis, Minnesota). The assay quantifies plasma NOx by measuring total nitrite after nitrate has been enzymatically reduced to nitrite via nitrate reductase.

\section{Data analysis}

All data are presented as mean \pm standard deviation (SD). A two-way, repeated-measures analyses of variance (ANOVA) was used to test for between trial differences in plasma NOx concentrations; 3 trials (BTJ vs. BF vs. PLA) by 6 time points (baseline, 1, 2, 3, 5 and $8 \mathrm{~h}$ post-ingestion). In the event of a significant interaction effect (trial $\times$ time), Fisher LSD post hoc analysis was performed to locate pairwise differences occurred. Statistical significance was set at $P<0.05$ prior to analyses. All analysis was performed with IBM SPSS statistics 20 for Windows (Surrey, UK).

\section{Results}

Inspection of food diaries indicated that participants complied with the imposed dietary restrictions and that their intakes did not differ between trials. No adverse events were reported with any of the supplements.

\section{Betanin content and bioavailability}

Betanin was identified in both the BTJ and BF with LCMS analysis (Fig. 3). Total betanin content for the BTJ and BF is presented in Table 2. Based on these analyses, each bottle of BTJ $(250 \mathrm{ml})$ and serving of BF $(300 \mathrm{~g})$ contained $\sim 194$ and $\sim 66 \mathrm{mg}$ of betanin, respectively. No betanin was detected in the PLA used in this study. Betanin could also not be detected in the plasma samples obtained after BTJ, BF or PLA consumption (data not shown).

\section{Composition of beetroot juice and whole beetroot food}

Antioxidant capacity, phenolic content, total betalain and total betaxanthin content for the BTJ, BF and PLA are presented in Table 2. According to these data, each serving of beetroot juice $(250 \mathrm{ml}$ ) had a TEAC of $\sim 3 \mathrm{mmol} / \mathrm{l}$ and contained $\sim 405 \mathrm{mg}$ GAE equivalents of phenolic compounds, $\sim 17 \mathrm{mg}$ of betacyanins and $\sim 10 \mathrm{mg}$ of betaxanthins. The analysis of the $\mathrm{BF}$ showed that the $300 \mathrm{~g}$ serving of $\mathrm{BF}$ fed to participants had a TEAC of $\sim 1.01 \mathrm{mmol} / \mathrm{L}$, contained $\sim 501 \mathrm{mg}$ of GAE of phenols, $\sim 59 \mathrm{mg}$ of betacyanins and $\sim 22.5 \mathrm{mg}$ of betaxanthins. The PLA contained a small number of phenolic compounds ( 43 mg); however, betalains could not be detected and the TEAC was low $(<0.5 \mathrm{mmol} / \mathrm{L})$.

\section{Plasma NOx concentrations}

Data are presented in Fig. 4. At baseline $(0 \mathrm{~h})$, concentrations of plasma NOx were similar between trials $(P>0.05)$. In the PLA trial, there was no change in plasma NOx concentrations at any time point $(P>0.05)$; however, after ingestion of both BTJ and BF there was an increase in plasma NOx compared to baseline (time effects; $P<0.001$ ) and PLA (drink $\mathrm{x}$ time interaction; $P<0.001$ ). Plasma NOx reached peak concentrations $2 \mathrm{~h}$ post-ingestion in both the BTJ and BF groups $(P<0.001 ; 163.7 \pm 46.9$ and $189.4 \pm 72.8 \mu \mathrm{mol} / \mathrm{L}$, respectively) and were still elevated above baseline values at $8 \mathrm{~h}$ post with BTJ $(P<0.001)$ and $5 \mathrm{~h}$ post with $\mathrm{BF}(P=0.012)$ (Fig. 4).

\section{Discussion}

The present study aimed to determine the plasma bioavailability of nitrate and betanin after consuming a commercially available BTJ and BF. Both the BTJ and BF were rich in betalains, particularly betanin; however, betanin could not be detected in plasma following consumption. Conversely, and in line with other research, ingestion of 
A

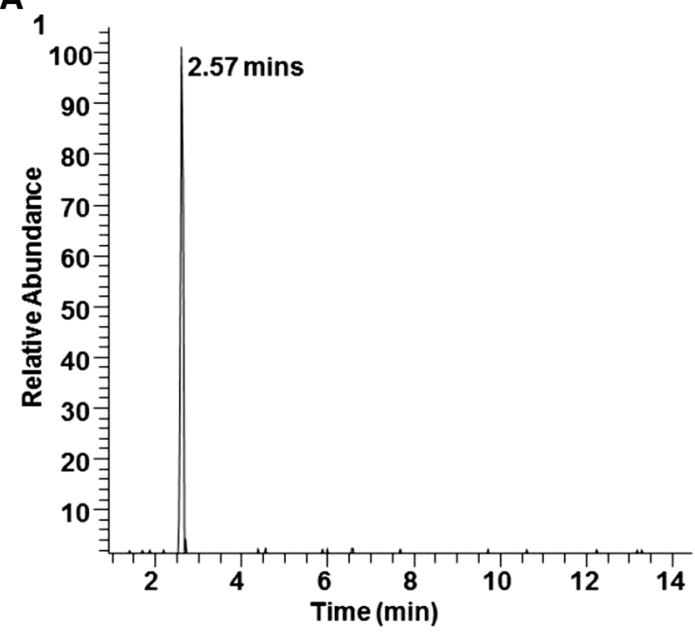

B

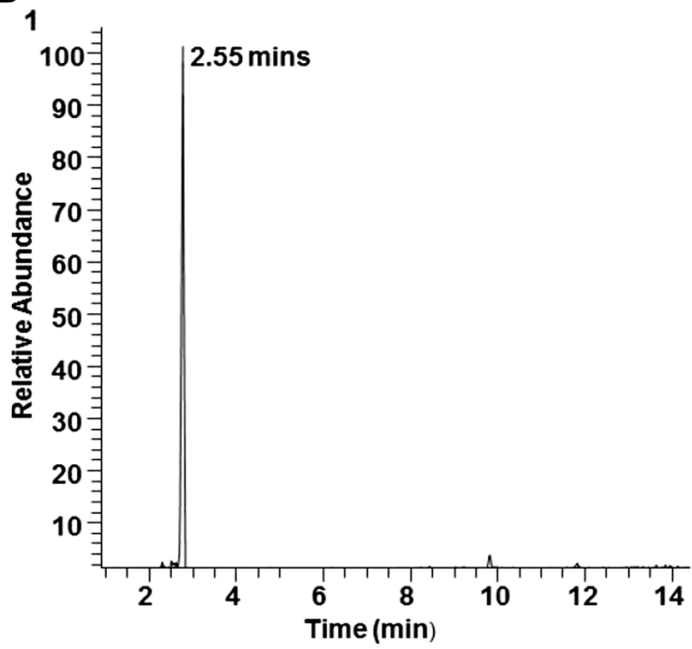

C

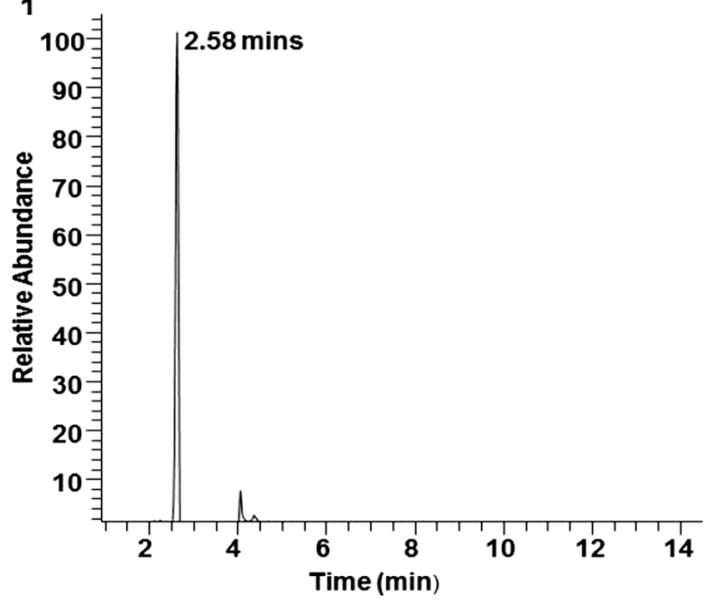

Fig. 3 a 1 LCMS chromatograms of betanin standard $(\mathrm{RT}=2.57 \mathrm{~min})$. (2) MS output of betanin standard (base peak $\mathrm{m} / \mathrm{z}$ 548.5-549.5) b (1) betanin in BTJ (RT = 2.55). (2) MS output for
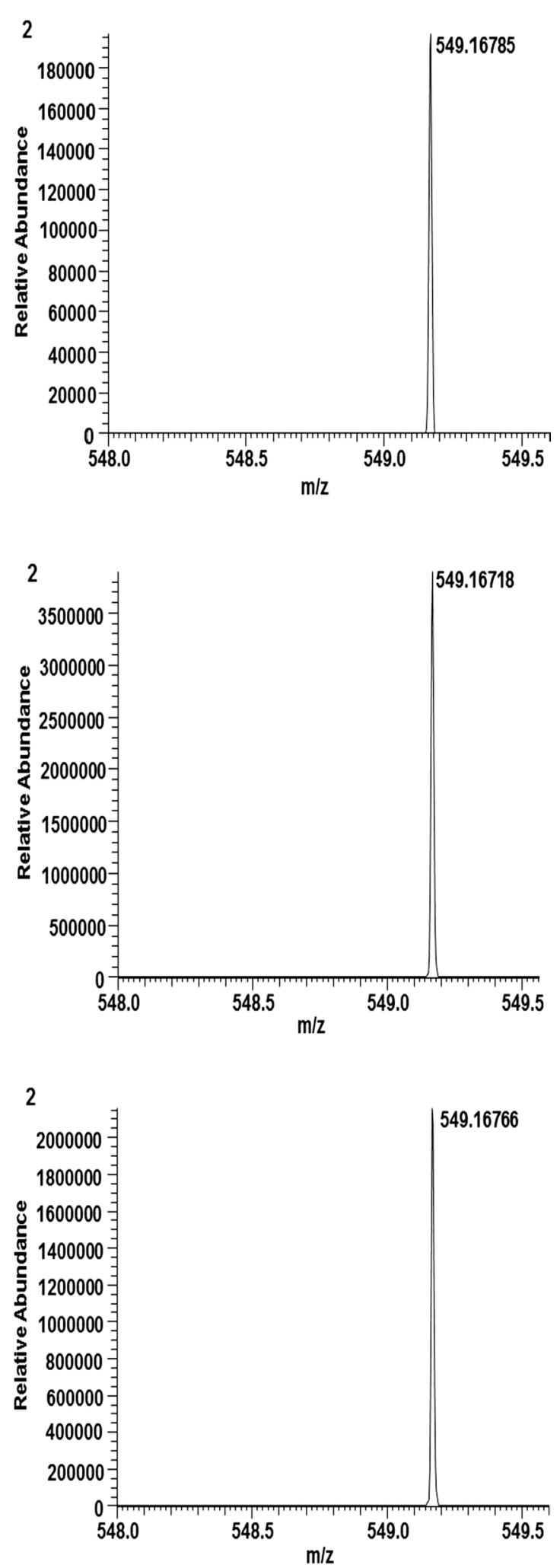

BTJ (base peak m/z 548.5-549.5) c (1) betanin in BF $(\mathrm{RT}=2.56)(2)$ MS output for BF (base peak m/z 548.5-549.5) 
Table 2 Trolox equivalence antioxidant activity (TEAC), total polyphenols (TPC), betanin, betacyanin and betaxanthin content of beetroot juice (BTJ), beetroot food (BF) and placebo (PLA)

\begin{tabular}{lcclll}
\hline Treatment & TEAC $(\mathrm{mmol} / \mathrm{L})$ & TPC $(\mathrm{mg} / \mathrm{GAE} / \mathrm{L})$ & Betanin $(\mathrm{mg} / \mathrm{L})$ & $\begin{array}{l}\text { Total betaxanthins } \\
\text { (mg indicaxanthin equivalents/L) }\end{array}$ & $\begin{array}{l}\text { Total betacyanins } \\
(\mathrm{mg} \text { betanin equivalents/L) }\end{array}$ \\
\hline Beetroot juice & $11.4 \pm 0.2$ & $1606.9 \pm 151$ & $777.9 \pm 41.3$ & $41.7 \pm 0.7$ & $68.2 \pm 0.4$ \\
Beetroot food & $3.4 \pm 0.4$ & $1.7 \pm 0.1$ & $221.3 \pm 23$ & $7.5 \pm 0.2$ & $19.6 \pm 0.6$ \\
Placebo & $0.25 \pm 0.02$ & $172.3 \pm 13.3$ & $\mathrm{ND}$ & $\mathrm{ND}$ & $\mathrm{ND}$ \\
\hline
\end{tabular}

Values are mean $\pm \mathrm{SD}$

TEAC BTJ mmol/L, BF $\mu \mathrm{mol} / \mathrm{g}$, TPC BTJ, $\mathrm{mg}$ gallic acid equivalent/L, BF mg gallic acid equivalent $/ \mathrm{g}$, Betanin BTJ, $\mathrm{mg} / \mathrm{L}, B F \mathrm{mg} / \mathrm{kg}$, Total betaxanthins BTJ, mg indicaxanthin equivalents/L, $B F \mathrm{mg}$ indicaxanthin equivalents/100 g fresh weight, Total betacyanins BTJ, mg betanin equivalents/L, $B F \mathrm{mg}$ betanin equivalents/100 $\mathrm{g}$ fresh weight

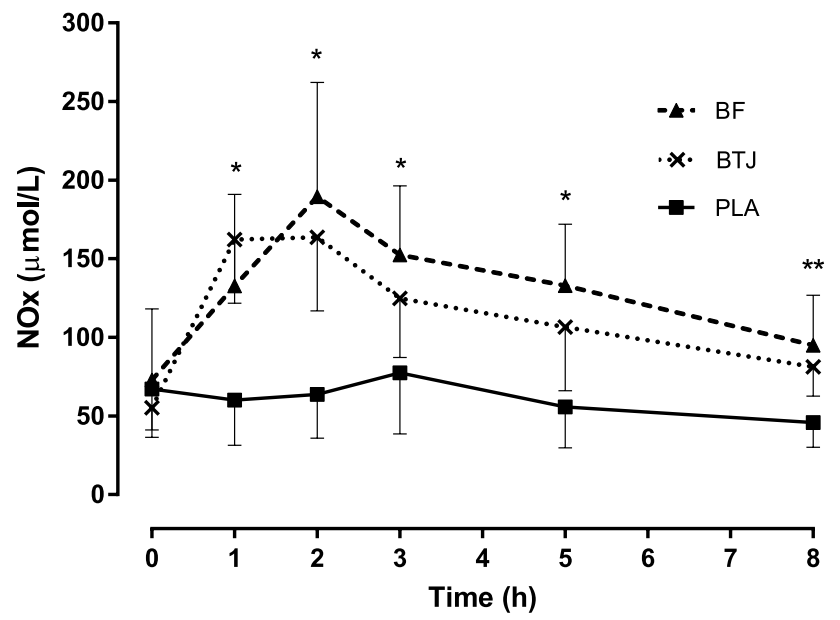

Fig. 4 Plasma NOx concentrations after beetroot juice (BTJ), beetroot food (BF) and placebo (PLA) ingestion. Data are mean $\pm \mathrm{SD}$; *BTJ and BF higher than PLA $(P<0.05)$, **BTJ higher than PLA $(P<0.05)$

BTJ and BF evoked elevations in plasma NOx levels compared to a placebo. Both BTJ and BF were found to contain significant amounts of polyphenols and antioxidant compounds. The present findings provide new information regarding the bioavailability and phytochemical content of two commonly consumed beetroot products.

Antioxidant capacity of the BTJ, BF and PLA was measured using the TEAC assay. Although this was not a primary aim of this study, we felt that this information would be useful for comparisons with other antioxidantrich foods. The TEAC assay estimates AC by comparing the intervention's scavenging ability to the Trolox standard [31] and is commonly used to provide an index of a food or beverage antioxidant potential [31, 32]. The analysis revealed the TEAC for BTJ ( $\sim 11.4 \mathrm{mmol} / \mathrm{L})$ to be higher than values reported for iced tea, green tea, apple juice, cranberry juice and orange juice $(4-10 \mathrm{mmo} / \mathrm{L})$, but lower than acai juice, black cherry juice, blueberry juice and pomegranate juice (12-40 $\mathrm{mmol} / \mathrm{L}$ ) (Seeram et al. 2008). Based on data from Pellegrini et al. [32], the
BF had a higher TEAC $(\sim 3.4 \mathrm{mmol} / \mathrm{L})$ than several whole vegetables, including tomatoes, radish, potato, onion, lettuce, leek, green beans, artichokes, avocado, broccoli, cabbage, carrot and cauliflower. Interestingly, the TEAC of a number of commonly consumed fruits, such as apples ( $\sim 1.45 \mathrm{mmol} / \mathrm{L})$, bananas and pears, were also found to be lower than the BF [32]. However, as seen with the BTJ, berried fruits such as blackberry, strawberry and raspberry exhibited a significantly higher AC than BF. Furthermore, the $\mathrm{BF}$ had a lower $\mathrm{AC}$ than the reported values for fresh beetroot extracts $(\sim 3.4$ vs. $\sim 5.21 \mathrm{mmol} / \mathrm{L})$ but similar to a cooked beetroot extract ( $2.94 \mathrm{mmol} / \mathrm{L})$ [32]. This suggests that some of the active compounds in beetroot are lost or perhaps degraded during cooking and processing. Conceptually, thermal treatment, exposure to bacterial agents, acidification, storage conditions, and modified atmospheric treatment could all affect phytochemical composition [33, 34]. Despite this, the BF and BTJ in particular still possess reasonably high antioxidant capacities in comparison with other fruit and vegetables and may therefore be favourable sources for boosting antioxidant defences and protecting against conditions associated with oxidative damage.

The antioxidant activity of the BTJ and BF can probably be ascribed to the high concentration of polyphenols and betalains they contain (see Table 2) and also to any synergistic interactions that might occur with these compounds, as has been suggested previously [35]. As our main focus was on betanin, quantifying individual polyphenols in the BTJ and BF was beyond the scope of this study. However, according to data from previous investigations, the main polyphenols in beetroot are phenolic acids (ferulic acid, chlorogenic acid, caffeic acid) and flavonoids (epicatechin, rutin, betagarin) $[29,35]$, many of which possess high antioxidant potential [36, 37]. Furthermore, the polyphenols in beetroot appear to be well absorbed in humans. Netzel et al. [38] reported that $51 \%$ of the total phenolics (about $338 \mathrm{mg}$ ) ingested from a homemade beetroot juice were detectable in the participants urine, indicating that several of the polyphenols present in beetroot may be absorbed and made available in the circulation for physiological effects. 
Both the juice and food were rich in betalain compounds (Table 2). In accordance with studies on fresh beetroot extracts, the betaxanthin content of BTJ and BF was much lower than the betacyanin content [39]. Betacyanins appear to be stronger antioxidants than betaxanthins $[10,39]$ and were likely major contributors to the antioxidant activity demonstrated by the BTJ and BF. Interestingly, the betanin content of BTJ was much higher than BF ( 194 mg vs. $\sim 66 \mathrm{mg}$ per serving). The reason for this is unclear, but is probably due to differences in how the products are processed or possibly the extraction methods used for analysis. Regardless, the higher TEAC values for BTJ versus BF are probably due to its comparatively higher betanin content. The antioxidant potential of betanin is believed to be higher than other betalains present in beetroot $[10,14,17]$.

To our knowledge, this is the first study that has characterised the bioavailability of betanin in human plasma following beetroot consumption. Despite the relatively high amount of betanin present in both the BTJ and BF, it could not be identified in the plasma at any time point after consumption (1-8 h). Our findings conflict with those of a previous study, in which betanin was identified in plasma at relatively high concentrations $(\sim 0.2 \mu \mathrm{mol} / \mathrm{l}) 2 \mathrm{~h}$ after consuming $500 \mathrm{~g}$ of fresh cactus pear fruit containing $16 \mathrm{mg}$ of betanin [40]. However, the discrepant findings between this study and the present investigation could be related to differences in the foods analysed (i.e. cactus pear fruit versus beetroot). This is supported by recent work from Tesoriare et al. [41] who compared the absorption rates of betanin from cactus pear fruit and red beetroot in a simulated in vitro model of the intestinal wall. They showed that epithelial transport was much lower when betanin was derived from red beetroot, speculating that the rate of absorption was inhibited by beetroot's food matrix. This suggests that the bioavailability of betanin may be lower after beetroot consumption compared to other sources of betanin.

Nevertheless, our inability to identify betanin in the plasma suggests that it may be lost or degraded during digestive processes. Previous studies investigating the renal elimination of betalains have indicated that betanin may instead be absorbed as downstream metabolites [17]. Kanner et al. [17] found that after consuming a betaninrich beetroot juice, isobetanin, but not betanin, could be detected in urine. The authors suggested that betanin undergoes isomerisation to isobetanin in the intestinal milieu and may therefore be the major metabolite absorbed after betanin ingestion. In addition to isomerisation, there are several other metabolic processes that could degrade betanin and limit its systemic bioavailability, including glycosidase enzyme activity from cellulase [17] or the presence of the pancreatic enzyme amylase [33]. Such data support the possibility that betanin is largely metabolised to secondary compounds prior to entering the circulation, which would provide a potential explanation as to why we were unable to detect betanin in the present study. This raises doubts as to whether the wide array of biological effects displayed by betanin in vitro can be extrapolated to in vivo conditions. Instead, the in vivo biological activity displayed by betanin in some studies [42, 43] could be mostly due to the biological effects of secondary betanin metabolites, although this remains to be elucidated. At present, data on the bioavailability of these metabolites or their potential biological activity are not yet available. Unfortunately, we were unable to unequivocally identify any metabolites of betanin in this study due to appropriate standards for HPLC/LCMS detection not being available. Thus, whether metabolites of betanin reached the circulation in the present study is purely speculative until clarified with future research. The development of new methodologies, analytical techniques and suitable standards will be required to establish the presence of these compounds.

Plasma NOx activity was significantly augmented after consumption of both BTJ and BF compared to the placebo (Fig. 3). These findings agree with a previous study that reported a rapid rise in NOx activity $1-3 \mathrm{~h}$ after BTJ ingestion [8]. Collectively these data are important, because an increase in the endogenous NOx pool is associated with a range of physiological effects that might be beneficial to health, such as improved endothelial function, reduced blood pressure, enhanced mitochondrial efficiency and improved metabolic function [5].

We acknowledge that a potential limitation of this study is the absence of any measures of urinary excretion. Therefore, we cannot rule out the possibility that betanin would have been detectable in excreted urine had we collected samples after beetroot consumption. Because the urinary elimination of betanin has been described before [17, 38], we chose to focus specifically on plasma bioavailability, which to the best of our knowledge, has not been characterised after beetroot consumption. We also acknowledge that restricting our analysis to $8 \mathrm{~h}$ post-consumption is a possible limitation because betanin might have appeared in the plasma at later time points. However, we feel that this is unlikely based on previous work in cactus pear fruit that showed plasma betanin concentration peaked at $3 \mathrm{~h}$ postconsumption and was undetectable at $8 \mathrm{~h}$ post [40]. Finally, our analysis focused exclusively on betanin and nitrate, and it was beyond the scope of this study to analyse individual phenolic and betalainic compounds present in beetroot. However, we acknowledge that these are not the only compounds in beetroot that have the potential to exert beneficial physiological effects. We therefore thought it prudent to describe the total phenolic, antioxidant capacity and betalainic content of these foods to demonstrate that there are in fact other phytonutrients in these foods. However, 
further research is required to delineate the individual bioactive compounds present in these particular foods.

Despite the aforementioned limitations, the data presented in this study provide new information on the bioavailability and phytochemical content of commercially available beetroot juice and whole food and will serve to stimulate further research into the effects of beetroot, while also being useful to practitioners interested in the potential health benefits of these products. Future research on the bioavailability of betanin metabolites and their potential for biological activity are required to further exude the potential usefulness of beetroot foods for health.

Acknowledgments This study was funded as part of a doctoral degree that receives financial support from Gs Fresh Ltd. The funders supplied the treatments used in this study but had no role in the conception of the study, its design, preparation, analysis and writing of the manuscript. The authors declare no conflict of interest. The authors wish to thank all the volunteers for their participation.

Open Access This article is distributed under the terms of the Creative Commons Attribution 4.0 International License (http://creativecommons.org/licenses/by/4.0/), which permits unrestricted use, distribution, and reproduction in any medium, provided you give appropriate credit to the original author(s) and the source, provide a link to the Creative Commons license, and indicate if changes were made.

\section{References}

1. Ninfali P, Angelino D (2013) Nutritional and functional potential of Beta vulgaris cicla and rubra. Fitoterapia 89:188-199. doi:10.1016/j.fitote.2013.06.004

2. Clifford T, Howatson G, West DJ, Stevenson EJ (2015) The potential benefits of red beetroot supplementation in health and disease. Nutrients 7(4):2801-2822. doi:10.3390/nu7042801

3. Lidder S, Webb AJ (2013) Vascular effects of dietary nitrate (as found in green leafy vegetables and beetroot) via the nitratenitrite-nitric oxide pathway. Br J Clin Pharmacol 75(3):677-696

4. Lundberg JO, Weitzberg E, Gladwin MT (2008) The nitratenitrite-nitric oxide pathway in physiology and therapeutics. Nat Rev Drug Discov 7(2):156-167

5. Weitzberg E, Lundberg JO (2013) Novel aspects of dietary nitrate and human health. Annu Rev Nutr 33:129-159. doi:10.1146/annurev-nutr-071812-161159

6. Webb AJ, Patel N, Loukogeorgakis S, Okorie M, Aboud Z, Misra S, Rashid R, Miall P, Deanfield J, Benjamin N (2008) Acute blood pressure lowering, vasoprotective, and antiplatelet properties of dietary nitrate via bioconversion to nitrite. Hypertension 51(3):784-790

7. Siervo M, Lara J, Ogbonmwan I, Mathers JC (2013) Inorganic nitrate and beetroot juice supplementation reduces blood pressure in adults: a systematic review and meta-analysis. J Nutr 143(6):818-826. doi:10.3945/jn.112.170233

8. Joris PJ, Mensink RP (2013) Beetroot juice improves in overweight and slightly obese men postprandial endothelial function after consumption of a mixed meal. Atherosclerosis 231(1):7883. doi:10.1016/j.atherosclerosis.2013.09.001

9. Kapil V, Weitzberg E, Lundberg J, Ahluwalia A (2014) Clinical evidence demonstrating the utility of inorganic nitrate in cardiovascular health. Nitric Oxide 38:45-57
10. Esatbeyoglu T, Wagner AE, Schini-Kerth VB, Rimbach G (2015) Betanin-A food colorant with biological activity. Mol Nutr Food Res 59(1):36-47. doi:10.1002/mnfr.201400484

11. Szaefer H, Krajka-Kuzniak V, Ignatowicz E, Adamska T, BaerDubowska W (2014) Evaluation of the effect of beetroot juice on DMBA-induced damage in liver and mammary gland of female Sprague-Dawley rats. Phytother Res 28(1):55-61. doi:10.1002/ ptr.4951

12. Lechner JF, Wang LS, Rocha CM, Larue B, Henry C, McIntyre CM, Riedl KM, Schwartz SJ, Stoner GD (2010) Drinking water with red beetroot food color antagonizes esophageal carcinogenesis in N-nitrosomethylbenzylamine-treated rats. J Med Food 13(3):733-739. doi:10.1089/jmf.2008.0280

13. Vidal PJ, Lopez-Nicolas JM, Gandia-Herrero F, Garcia-Carmona F (2014) Inactivation of lipoxygenase and cyclooxygenase by natural betalains and semi-synthetic analogues. Food Chem 154:246-254. doi:10.1016/j.foodchem.2014.01.014

14. Esatbeyoglu T, Wagner AE, Motafakkerazad R, Nakajima Y, Matsugo S, Rimbach G (2014) Free radical scavenging and antioxidant activity of betanin: electron spin resonance spectroscopy studies and studies in cultured cells. Food Chem Toxicol 73:119 126. doi:10.1016/j.fct.2014.08.007

15. Georgiev VG, Weber J, Kneschke EM, Denev PN, Bley T, Pavlov AI (2010) Antioxidant activity and phenolic content of betalain extracts from intact plants and hairy root cultures of the red beetroot Beta vulgaris cv. Detroit dark red. Plant Foods Hum Nutr 65(2):105-111. doi:10.1007/s11130-010-0156-6

16. Pavlov A, Kovatcheva P, Georgiev V, Koleva I, Ilieva M (2002) Biosynthesis and radical scavenging activity of betalains during the cultivation of red beet (Beta vulgaris) hairy root cultures. Z Naturforsch 57(7-8):640-644

17. Kanner J, Harel S, Granit R (2001) Betalains-a new class of dietary cationized antioxidants. J Agric Food Chem 49(11):5178-5185

18. Kapadia GJ, Azuine MA, Rao GS, Arai T, Iida A, Tokuda H (2011) Cytotoxic effect of the red beetroot (Beta vulgaris L.) extract compared to doxorubicin (Adriamycin) in the human prostate (PC-3) and breast (MCF-7) cancer cell lines. Anti Cancer Agents Med Chem 11(3):280-284

19. Kapadia GJ, Rao GS, Ramachandran C, Iida A, Suzuki N, Tokuda H (2013) Synergistic cytotoxicity of red beetroot (Beta vulgaris L.) extract with doxorubicin in human pancreatic, breast and prostate cancer cell lines. J Complement Integr Med. doi:10.1515/jcim-2013-0007

20. Pietrzkowski Z, Spórna A, Stalica P, Tresher W, Jimenez R, Michaowski $T$ et al (2010) Influence of betalain-rich extraction on reduction of discomfort associated with osteoarthritis. New Med 1:12-17

21. van Velzen AG, Sips AJ, Schothorst RC, Lambers AC, Meulenbelt $\mathrm{J}$ (2008) The oral bioavailability of nitrate from nitrate-rich vegetables in humans. Toxicol Lett 181:177-181. doi:10.1016/j. toxlet.2008.07.019

22. Wylie LJ, Kelly J, Bailey SJ, Blackwell JR, Skiba PF, Winyard PG, Jeukendrup AE, Vanhatalo A, Jones AM (2013) Beetroot juice and exercise: pharmacodynamic and dose-response relationships. J Appl Physiol 115(3):325-336. doi:10.1152/ japplphysiol.00372.2013

23. Frank T, Stintzing FC, Carle R, Bitsch I, Quaas D, Strass G, Bitsch R, Netzel M (2005) Urinary pharmacokinetics of betalains following consumption of red beet juice in healthy humans. Pharm Res 52(4):290-297. doi:10.1016/j.phrs.2005.04.005

24. Brandwilliams W, Cuvelier ME, Berset C (1995) Use of a freeradical method to evaluate antioxidant activity. Food Sci Technol Leb 28(1):25-30

25. Shahidi F, Ho CT (2007) Antioxidant measurement and applications: an overview. Acs Sym Ser 956:2-7. doi:10.1021/bk-20070956.ch001 
26. Magalhaes PJ, Vieira JS, Goncalves LM, Pacheco JG, Guido LF, Barros AA (2010) Isolation of phenolic compounds from hop extracts using polyvinylpolypyrrolidone: characterization by high-performance liquid chromatography-diode array detection-electrospray tandem mass spectrometry. J Chromatogr A 1217(19):3258-3268. doi:10.1016/j.chroma.2009.10.068

27. Cai Y, Corke H (1999) Amaranthus betacyanin pigments applied in model food systems. J Food Sci 64(5):869-873. doi:10.1111/j.1365-2621.1999.tb15930.x

28. Mossammer MR, Stintzing FC, Carle R (2005) Development of a process for the production of a betalain-based colouring foodstuff from cactus pear. Innov Food Sci Emerg 2:221-231. doi:10.1016/j.ifset.2005.02.001

29. Kujala TS, Loponen JM, Klika KD, Pihlaja K (2000) Phenolics and betacyanins in red beetroot (Beta vulgaris) root: distribution and effect of cold storage on the content of total phenolics and three individual compounds. J Agric Food Chem 11:5338-5342

30. Kujala TS, Vienola MS, Klika KD, Loponen JM, Pihlaja K (2002) Betalain and phenolic compositions of four beetroot (Beta vulgaris) cultivars. Eur Food Res Technol 214(6):505-510. doi:10.1007/s00217-001-0478-6

31. van den Berg R, Haenen GRMM, van den Berg H, Bast A (1999) Applicability of an improved Trolox equivalent antioxidant capacity (TEAC) assay for evaluation of antioxidant capacity measurements of mixtures. Food Chem 66(4):511-517. doi:10.1016/S0308-8146(99)00089-8

32. Pellegrini N, Serafini M, Colombi B, Del Rio D, Salvatore S, Bianchi M, Brighenti F (2003) Total antioxidant capacity of plant foods, beverages and oils consumed in Italy assessed by three different in vitro assays. J Nutr 133(9):2812-2819

33. Tesoriere L, Fazzari M, Angileri F, Gentile C, Livrea MA (2008) In vitro digestion of betalainic foods. Stability and bioaccessibility of betaxanthins and betacyanins and antioxidative potential of food digesta. J Agric Food Chem 56(22):10487-10492. doi:10.1021/jf8017172

34. Osornio MML, Chaves AR (1998) Quality changes in stored raw grated beetroots as affected by temperature and packaging film. $\mathrm{J}$ Food Sci 63(2):327-330
35. Georgiev VG, Weber J, Kneschke E-M, Denev PN, Bley T, Pavlov AI (2010) Antioxidant activity and phenolic content of betalain extracts from intact plants and hairy root cultures of the red beetroot Beta vulgaris cv. Detroit dark red. Plant Foods Hum Nutr 65(2):105-111

36. Velioglu YS, Mazza G, Gao L, Oomah BD (1998) Antioxidant activity and total phenolics in selected fruits, vegetables, and grain products. J Agric Food Chem 46(10):4113-4117. doi:10.1021/Jf9801973

37. Gulcin I (2012) Antioxidant activity of food constituents: an overview. Arch Toxicol 86(3):345-391. doi:10.1007/ s00204-011-0774-2

38. Netzel M, Stintzing FC, Quaas D, Strass G, Carle R, Bitsch R, Bitsch I, Frank T (2005) Renal excretion of antioxidative constituents from red beet in humans. Food Res Int 38(8-9):10511058. doi:10.1016/j.foodres.2005.03.016

39. Stintzing FC, Carle R (2007) Betalains-emerging prospects for food scientists. Trends Food Sci Tech 18(10):514-525. doi:10.1016/j.tifs.2007.04.012

40. Tesoriere L, Allegra M, Butera D, Livrea MA (2004) Absorption, excretion, and distribution of dietary antioxidant betalains in LDLs: potential health effects of betalains in humans. Am J Clin Nutr 80(4):941-945

41. Tesoriere L, Gentile C, Angileri F, Attanzio A, Tutone M, Allegra M, Livrea MA (2013) Trans-epithelial transport of the betalain pigments indicaxanthin and betanin across Caco- 2 cell monolayers and influence of food matrix. Eur J Nutr 52(3):1077-1087. doi:10.1007/s00394-012-0414-5

42. Han JY, Ma DS, Zhang M, Yang XL, Tan DH (2015) Natural antioxidant betanin protects rats from paraquat-induced acute lung injury interstitial pneumonia. BioMed Res Int. doi:10.1155/2015/608174

43. Tan DH, Wang YH, Bai B, Yang XL, Han JY (2015) Betanin attenuates oxidative stress and inflammatory reaction in kidney of paraquat-treated rat. Food Chem Toxicol 78:141-146. doi:10.1016/j.fct.2015.01.018 